\title{
Validation of a quantitative FFQ for the Barbados National Cancer Study
}

\author{
Mohammadreza Pakseresht ${ }^{1}{ }^{\prime} \dagger$, Sangita Sharma ${ }^{2,3, *,} \dagger, \mathrm{Xia} \mathrm{Cao}^{1,3}$, Rachel Harris ${ }^{4}$, \\ Christian Caberto $^{3}$, Lynne R Wilkens ${ }^{3}$, Anselm JM Hennis ${ }^{4,5}$, Suh-Yuh Wu ${ }^{5}$, \\ Barbara Nemesure ${ }^{5}$ and M Cristina Leske ${ }^{5}$, Barbados National Cancer Study Group \\ 'Nutrition Research Institute, Department of Nutrition, University of North Carolina at Chapel Hill, Kannapolis, \\ NC 28081, USA: ${ }^{2}$ Department of Medicine, 1-126 Li Ka Shing Centre for Health Research Innovation, \\ University of Alberta, Edmonton, AB T6G 2E1, Canada: ${ }^{3}$ Epidemiology Program, Cancer Research Center of \\ Hawaii, University of Hawaii, Honolulu, HI, USA: ${ }^{4}$ Barbados National Cancer Study, Winston Scott Polyclinic \\ and Chronic Disease Research Center, University of the West Indies, St Michael, Barbados: ${ }^{5}$ Department of \\ Preventive Medicine, University Medical Center at Stony Brook, Stony Brook, NY, USA
}

Submitted 11 November 2009: Accepted 30 June 2010: First published online 15 September 2010

\begin{abstract}
Objective: To assess the validity of a 148-item quantitative FFQ (QFFQ) that was developed for the Barbados National Cancer Study (BNCS) to determine dietary intake over 12 months and examine the dietary risk factors.

Design: A cross-sectional validation study of the QFFQ against $4 \mathrm{~d}$ food diaries. Spearman's rank correlations $(\rho)$, intra-class correlation coefficients (ICC) and weighted $\kappa$ were computed as measures of concordance, adjusting for daily variations in the food diaries. Cross-classification tables and Bland-Altman plots were created for further assessment.

Setting: BNCS is a case-control study of environmental risk factors for breast and prostate cancer in a predominantly African-origin population in Barbados.

Subjects: Fifty-four individuals (21 years and older) were recruited among controls in the BNCS who were frequency-matched on sex and age group to breast and prostate cancer cases.

Results: Similar mean daily energy intake was derived from the food diary $(8201 \mathrm{~kJ}$ $(1960 \mathrm{kcal}))$ and QFFQ $(7774 \mathrm{~kJ}(1858 \mathrm{kcal}))$. Rho for energy and macronutrients ranged from $0 \cdot 66$ (energy) to $0 \cdot 17$ (dietary fibre). The percentage of energy from carbohydrates and protein showed the highest and lowest ICC among macronutrients $(0.63$ and $0 \cdot 27$, respectively). The highest weighted $\kappa$ was observed for energy $(0 \cdot 45)$. When the nutrient intake was divided into quartiles, approximately $34 \%$ of the observations were in the same quartile.

Conclusions: This investigation supports the validity of the QFFQ as a method for assessing long-term dietary intake except for dietary fibre, folate, vitamins A, E and $\mathrm{B}_{12}$. The instrument will be a useful tool in the analysis of diet-cancer associations in the BNCS.
\end{abstract}

Keywords
Quantitative FFQ
Food diary
Validity
Barbados National Cancer Study
The Barbados National Cancer Study (BNCS) is a populationbased case-control study designed to examine the genetic and environmental risk factors for breast and prostate cancer in a predominantly African-origin population. The importance of nutrition-related factors and growing interest in the role of nutrient-gene interactions in cancer aetiology necessitates the development of a valid method for assessing long-term dietary intake. Studies on the association between diet and cancer have not been performed in Barbados, West Indies, likely due, in part, to the lack of a validated method to assess long-term dietary intake.

$\dagger$ Joint first authors.
To fill this gap, a 148-item quantitative FFQ (QFFQ) was developed to determine dietary intake and to examine hypotheses related to diet and its interaction with genes and cancer in African-Barbadians ${ }^{(1)}$. QFFQ is commonly used in large-scale epidemiological studies and provides a feasible approach to assess the usual long-term dietary intake of a population ${ }^{(2)}$. Only valid instruments provide correct estimates of diet and diet-cancer associations. Although a gold standard to validate QFFQ currently does not exist, its validity is evaluated by comparing the results of these instruments to those using other dietary assessment methods or biomarkers ${ }^{(3,4)}$. Only dietary assessment methods were included in the present investigation as the 
collection and evaluation of biomarkers was beyond the scope of the present study.

The aim of the present study was to assess the validity of the 148-item QFFQ developed for the BNCS against $4 \mathrm{~d}$ food diaries.

\section{Subjects and methods}

\section{Sampling}

Sampling procedures have been reported previously ${ }^{(1,5)}$. In brief, fifty-four individuals (21 years and older) were recruited among controls in the BNCS who were frequencymatched on sex and age group to breast and prostate cancer cases. Pregnant and breast-feeding women were excluded. The recruited participants were invited to complete both the QFFQ and a $4 \mathrm{~d}$ food diary.

\section{Data collection}

\section{Quantitative FFQ collection}

The methods for the QFFQ data collection have been described elsewhere ${ }^{(1)}$. Briefly, the QFFQ was developed using $24 \mathrm{~h}$ recalls from over 1600 Barbados Food Consumption and Anthropometric Survey participants; additional details on its development have been published ${ }^{(1)}$. Then the QFFQ was administered by a trained dietitian and three nurses. The data collectors were trained for $5 \mathrm{~d}$ in the administration of the instrument and a manual of procedures was developed to document all data collection protocols. To ensure standardization, each interviewer practised administering multiple QFFQ under the supervision of the principal investigator (S.S.).

The QFFQ included 148 food items to assess usual food and drink intake over the past 12 months. Eight frequency category choices were given for each food item and ranged from 'never ( $<1$ time a month)' to ' $\geq 2$ times a day'. Portion sizes were determined using household units (e.g. tablespoon or coffee mug), food models (developed specifically to represent foods consumed in Barbados) or standardized portions (e.g. slice of bread) for thirty-three, sixty-four and fifty-one items, respectively. The QFFQ takes approximately 35 min to administer.

\section{Food diary collection}

Procedures for food diary data collection have been described elsewhere ${ }^{(5)}$. In brief, a trained dietitian visited the homes of participants who agreed to complete the $4 \mathrm{~d}$ food diary within 1 week of the QFFQ completion. The dietitian reviewed the methods for completing the diary and showed the participant an example of a completed instrument. Each participant was asked to record all foods and drinks consumed at the time of consumption and to estimate the portion sizes based on standard household measures. The dates for the completion of the diary were the four consecutive days after the instructions were provided. The dietitian visited the home of each respondent the day after the diary was completed and clarified all foods and drinks recorded, particularly with regard to brand names, amounts consumed and the time of consumption. The dietitian also double-checked information about missing data and frequently forgotten items, such as whether the skin on the chicken had been consumed or the type of milk (e.g. non-fat, low-fat) added to tea or coffee.

The study was approved by the Institutional Review Board of the University of the West Indies-Cave Hill/ Barbados Ministry of Health, the Stony Brook University Committee on Research Involving Human Subjects and the University of Hawaii Committee of Human Studies. All participants signed informed consent forms before being interviewed.

\section{Analyses}

Data analyses were performed using the SAS statistical software package version 9.1 (SAS Institute, Cary, NC, USA) and the STATA MP statistical software package version $10 \cdot 1$ (StataCorp., College Station, TX, USA).

\section{Computation of daily nutrient intake from the qualitative FFQ: food composition database}

A food composition database (FCD) was constructed specifically for the QFFQ. Each of the 148 food items had a record in the FCD that provided the amount of nutrients per $100 \mathrm{~g}$ of food. For food items that represented food groups, such as doughnuts, currant slices and jam puffs, the records were averages of the food composition of the relevant foods, weighted by the frequency of consumption based on previously collected data ${ }^{(1)}$. Sources of food composition data included the US Department of Agriculture (USDA) National Nutrient Database for Standard Reference, Release 18 and the USDA Survey Nutrient Database (What We Eat in America, the National Health and Nutrition Examination Survey (NHANES) 2001-2002) ${ }^{(6,7)}$, the Nutribase nutrient database (Nutribase, 2004) and the Barbados food composition data ${ }^{(8)}$.

Computation of daily nutrient intake from $4 d$ food diary All food diary data were coded, entered and analysed using Nutribase Clinical Nutrition Manager version 5.18 (CyberSoft Inc., Phoenix, AZ, USA). The food composition tables in Nutribase were updated to include weighed recipes that were previously collected in Barbados ${ }^{(8)}$. Nutribase calculated the nutrient intake/diary day per person based on the USDA food composition table. The daily intake used in the present analysis was the average intake of all food diaries combined.

\section{Nutrient computation}

Daily intake of each food item was determined for each subject. The frequency categories in the QFFQ were converted to monthly frequencies (Fig. 1). For each seasonal food, the monthly frequencies were adjusted by 


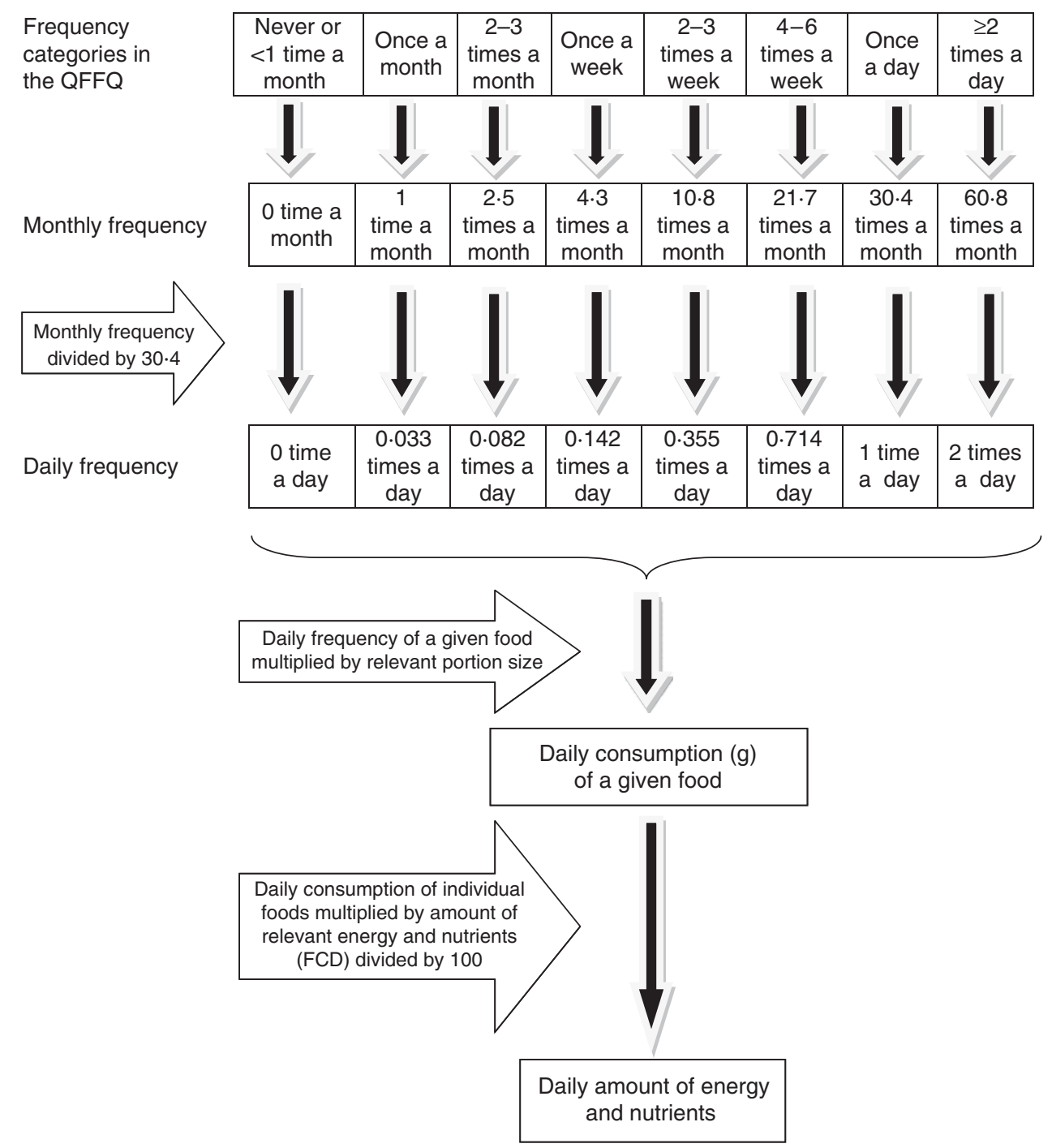

Fig. 1 Algorithm for computing daily nutrient intake (QFFQ, quantitative FFQ; FCD, food composition database)

multiplying the proportion of months per year for which the food item was available.

Daily grams were computed for each food item as the daily frequency (monthly frequency divided by $30 \cdot 4$ ) multiplied by the portion size converted to grams. The amount of nutrients consumed per day was computed by food item for each participant by applying the FCD. The daily grams were multiplied by the amount of nutrient per $100 \mathrm{~g}$ of the food item divided by 100 . Total daily intake for each participant was obtained by summing the amount for each nutrient across the 148 food items.

\section{Statistical methods}

Several measures of concordance were used to compare the nutrient intake from the QFFQ and the average from the $4 \mathrm{~d}$ food diary. Spearman's rank correlation coefficients $(\rho)$ and intra-class correlation coefficients (ICC) of the logged values were computed for energy, seventeen nutrients and the percentages of energy from protein, carbohydrate and fat ${ }^{(9)}$. Rho measures correlation, whereas the ICC measures agreement. Rho and ICC were adjusted for within-person daily variability by multiplying by an adjustment factor $^{(2)}$. The correlation coefficients for men and women were adjusted for age to account for differences in the age distributions between these groups.

The adjustment factor was computed from the $4 \mathrm{~d}$ diary information. The QFFQ determines mean daily dietary intake and does not provide within-person variance in the diet. The adjustment factor was calculated using the following formula: $\left[1+\left(\left(\sigma_{\mathrm{W}}^{2} / \sigma_{\mathrm{B}}^{2}\right) / m\right)\right]^{1 / 2}$, where $m$ was the average number of days covered by the food diary and the within-person $\left(\sigma_{\mathrm{W}}^{2}\right)$ and between-person $\left(\sigma_{\mathrm{B}}^{2}\right)$ variances were computed from the $4 \mathrm{~d}$ food diaries by variance component techniques ${ }^{(10)}$.

As another measure of correlation, the degree of misclassification between the QFFQ and food diary data was evaluated by analysing cross-classification based on quartiles. The quartiles were created using instrument-specific 
distribution. The percentage in the same quartile and the weighted $\kappa$ were computed as measures of concordance. Kappa is the percentage agreement, adjusted for chance, and the weighted $\kappa$ accounts for different levels of agreement ${ }^{(11)}$.

Bland-Altman plots were used in addition to observe the agreement between the QFFQ and food diaries at the individual level. The measurement error is shown by plotting the individual differences between the pair of measurements against the mean difference of the paired measurements ${ }^{(12)}$.

\section{Results}

Of the fifty-four individuals invited to participate in the $4 \mathrm{~d}$ food diary data collection, two were subsequently not located, two declined (due to ill health) and one person did not complete the diary. Therefore, the response rate was $91 \%$. Of the forty-nine who participated, forty-four respondents completed the food diaries for at least $4 \mathrm{~d}$ (forty-two completed the $4 \mathrm{~d}$ diary, one completed $5 \mathrm{~d}$ and one completed $7 \mathrm{~d}$ ), two respondents completed $3 \mathrm{~d}$, two respondents completed $2 \mathrm{~d}$ and one respondent completed only $1 \mathrm{~d}$. We present the results using all fortynine participants. Exclusion of respondents who had recorded fewer than $4 \mathrm{~d}$ of dietary (five respondents) did not change the results (data not shown). The mean age of the forty-nine participants was 60 (SD 13) years, ranging from 36 to 85 years, and 53\% ( $n$ 26) were female. The participants provided $191 \mathrm{~d}$ of food diary data, which included 131 weekdays and sixty weekend days. Of the total, thirty-eight (88\%) respondents completed the food diaries on at least one weekend day.

Table 1 presents the mean and SD of energy and nutrient intake from the QFFQ and food diaries, as well as the $\rho$ and ICC between these two methods. Mean energy intake derived from the food diaries $(8201 \mathrm{~kJ}(1960 \mathrm{kcal}))$ was very similar to that from the QFFQ $(7774 \mathrm{~kJ}(1858 \mathrm{kcal}))$. The percentage of energy from total fat, carbohydrate and protein was the same when derived from the QFFQ and food diaries. Intake of vitamins $\mathrm{B}_{6}, \mathrm{C}$ and $\mathrm{D}$, total folate, selenium and zinc was higher from the QFFQ than from the food diary. For energy and macronutrients, the Spearman's rank correlations varied between $0.66(P<0 \cdot 0001)$ for energy and $0 \cdot 17(P>0 \cdot 05)$ for dietary fibre, whereas the ICC ranged from 0.63 for carbohydrate and the percentage of energy from carbohydrate to $0 \cdot 27$ for the percentage of energy from protein. The Spearman's rank correlations for micronutrients were somewhat lower and ranged from $0.52(P=0.005)$ for selenium to $-0.15(P>0 \cdot 05)$ for vitamin $\mathrm{A}$; ICC ranged between 0.47 for calcium and 0 for vitamins $A, D$ and $\mathrm{E}$, total folate and selenium. The average $\rho$ for all nutrients (QFFQ $v$. food diary) was $0 \cdot 38$, with a median of $0 \cdot 43$.

Table 1 also shows the results of the cross-classification analysis of all participants by quartiles of absolute intake obtained from the food diary and QFFQ. On average, $34.3 \%$ of the participants fell into the same categories and $6.5 \%$ of observations were grossly misclassified with an average weighted $\kappa$ of $0 \cdot 20$.

Analyses were also performed separately for men and women. Both men and women had similar mean intake of macronutrients from the food diaries and QFFQ, and higher values for micronutrients from the QFFQ (data not shown). The average age-adjusted correlation coefficient for all nutrients was similar for men and women $(0.34 v \cdot 0 \cdot 31$ for Spearman correlation; $0 \cdot 32 v \cdot 0 \cdot 31$ for ICC; data not shown).

Figure 2 illustrates the Bland-Altman plots of individual validity of the QFFQ $v$. the food diary for energy, fat, carbohydrate, protein, vitamins $\mathrm{C}$ and $\mathrm{B}_{6}$, calcium and iron based on log-transformed values. The plots indicate that at low intake, the QFFQ provided lower estimates for energy, carbohydrates, fat, protein and iron, but at higher intake it provided a higher estimate than the food diary. The scatter of differences tended to decrease with increased intake of vitamins $\mathrm{C}$ and $\mathrm{B}_{6}$, which indicated a closer agreement at higher intake. However, the estimation of intake of these two vitamins by the QFFQ was consistently higher than the food diary. For calcium, a divergence pattern of scattering difference was observed. However, on average the percentage of difference was almost zero between the two measurements. This indicates that in higher levels of intake, both dietary measurement tools estimated calcium intake with more prominent differences than at the lower level of intake. The estimated intake of energy, fat, carbohydrates and protein by the QFFQ was 6\% lower than that by the food diary.

\section{Discussion}

In the present study, we presented several measures of concordance between the QFFQ and the $4 \mathrm{~d}$ food diary: Spearman's correlation coefficients, ICC, cross-classification method, weighted $\kappa$ and Bland-Altman plots. For energy and all nutrients, the $\rho$, ICC and weighted $\kappa$ ranged from 0.66 to $-0 \cdot 15,0.63$ to 0 and 0.45 to -0.04 , respectively. The average $\rho$ for all nutrients was 0.38 and acceptable percentages of gross agreement were found between the two methods. Accordingly, the dietary intake of energy, carbohydrate, fat and saturated fat, as well as the proportion of energy from carbohydrate, will be estimated well by the QFFQ. Among micronutrients, the QFFQ will provide good estimates for vitamins $\mathrm{C}$ and $\mathrm{B}_{6}$, calcium and iron, but not for folate and vitamins $\mathrm{A}, \mathrm{E}$ and $\mathrm{B}_{12}$.

Comparing the two dietary assessment methods used in the present study, the average level of agreement between the quartiles of absolute nutrient intake was similar to or higher than that reported by studies on Korean ${ }^{(13)}$, American $^{(14)}$ and German ${ }^{(15)}$ populations. The mean proportion of classification into the same quartile for energy and macronutrients was higher in the present study (40\%) than in the Korean (37\%), American (38\%) and German (32\%) 
Table 1 Nutrient intake estimates and agreement between the food diaries and QFFQ

\begin{tabular}{|c|c|c|c|c|c|c|c|c|c|}
\hline \multirow[b]{3}{*}{ Dietary variables } & \multicolumn{4}{|c|}{ Measurement tools } & \multicolumn{5}{|c|}{ Correlation/agreement assessment methods } \\
\hline & \multicolumn{2}{|c|}{ QFFQ } & \multicolumn{2}{|c|}{ Food diary } & \multirow{2}{*}{$\begin{array}{c}\text { Spearman's rank } \\
\text { correlationt }\end{array}$} & \multirow{2}{*}{$\begin{array}{l}\text { Intra-class correlation } \\
\text { coefficienttł }\end{array}$} & \multicolumn{2}{|c|}{ Cross-classification $(\%)$} & \multirow[b]{2}{*}{ Weighted } \\
\hline & Mean & SD & Mean & SD & & & Same quartile & Opposite quartile & \\
\hline Energy (kJ) & 7774 & 3050 & 8200 & 2276 & $0 \cdot 66^{*}$ & 0.57 & 49 & 4 & 0.45 \\
\hline Total fat $(\mathrm{g})$ & 57 & 28 & 62 & 22 & $0.59^{*}$ & 0.59 & 35 & 2 & 0.25 \\
\hline Saturated fat $(\mathrm{g})$ & 16 & 9 & 16 & 8 & $0 \cdot 64^{*}$ & $0 \cdot 61$ & 35 & 4 & 0.25 \\
\hline Protein $(\mathrm{g})$ & 74 & 34 & 80 & 25 & $0 \cdot 44^{\star}$ & $0 \cdot 42$ & 39 & 4 & $0 \cdot 29$ \\
\hline Carbohydrate (g) & 255 & 102 & 273 & 93 & $0 \cdot 56^{*}$ & 0.63 & 35 & 4 & 0.32 \\
\hline Sugar $(g)$ & 105 & 54 & 105 & 55 & $0 \cdot 45^{\star}$ & 0.45 & 39 & 8 & 0.25 \\
\hline Dietary fibre $(\mathrm{g})$ & 26 & 10 & 23 & 11 & $0 \cdot 17$ & $0 \cdot 34$ & 35 & 10 & 0.09 \\
\hline$\%$ Energy from fat & 27 & 5 & 27 & 6 & $0 \cdot 42^{*}$ & 0.49 & 41 & 6 & $0 \cdot 29$ \\
\hline$\%$ Energy from protein & 16 & 3 & 16 & 3 & 0.27 & $0 \cdot 27$ & 33 & 8 & $0 \cdot 16$ \\
\hline$\%$ Energy from carbohydrate & 55 & 8 & 55 & 9 & $0 \cdot 50^{*}$ & 0.63 & 49 & 6 & $0 \cdot 35$ \\
\hline Vitamin A ( $\mu$ g_RAE) & 1539 & 876 & 1603 & 1221 & $-0 \cdot 15$ & 0.00 & 26 & 10 & -0.04 \\
\hline Vitamin C (mg) & 174 & 101 & 128 & 78 & $0.39^{\star}$ & $0 \cdot 29$ & 35 & 6 & 0.22 \\
\hline Vitamin $B_{6}(\mathrm{mg})$ & $2 \cdot 5$ & $1 \cdot 0$ & $1 \cdot 8$ & $0 \cdot 8$ & $0 \cdot 43^{\star}$ & $0 \cdot 13$ & 35 & 4 & 0.25 \\
\hline Vitamin $B_{12}(\mu \mathrm{g})$ & 46 & 45 & 65 & 33 & 0.05 & 0.01 & 26 & 8 & 0.00 \\
\hline Total folate (mg) & 352 & 142 & 185 & 100 & $0 \cdot 36^{\star}$ & 0.00 & 26 & 8 & $0 \cdot 13$ \\
\hline Vitamin D $(\mu \mathrm{g})$ & $1 \cdot 4$ & $1 \cdot 3$ & $1 \cdot 0$ & $1 \cdot 3$ & $0 \cdot 26^{\star}$ & 0.00 & 22 & 6 & 0.09 \\
\hline Vitamin E (mg_ATE) & 0.9 & 0.9 & $3 \cdot 6$ & $3 \cdot 2$ & 0.02 & 0.00 & 20 & 12 & -0.04 \\
\hline Calcium (mg) & 572 & 226 & 615 & 237 & $0 \cdot 49^{\star}$ & 0.47 & 35 & 4 & 0.25 \\
\hline Iron (mg) & 13 & 6 & 14 & 5 & $0 \cdot 39^{*}$ & $0 \cdot 35$ & 33 & 8 & $0 \cdot 19$ \\
\hline Selenium $(\mu \mathrm{g})$ & 106 & 55 & 79 & 75 & $0 \cdot 52^{\star}$ & 0.00 & 31 & 4 & $0 \cdot 22$ \\
\hline Zinc (mg) & $7 \cdot 7$ & $3 \cdot 3$ & $6 \cdot 7$ & $2 \cdot 6$ & 0.43 & $0 \cdot 20$ & 41 & 10 & 0.29 \\
\hline
\end{tabular}

RAE, retinol activity equivalent; ATE, $\alpha$-tocopherol equivalent.
${ }^{*} P<0$.05.

tAdjusted for day-to-day variation in the food diary data.

$\ddagger$ All correlations are based on log-transformed values.

$\S$ Statistics for cross-classification were based on instrument-specific quartile cut-off points. 
(a)

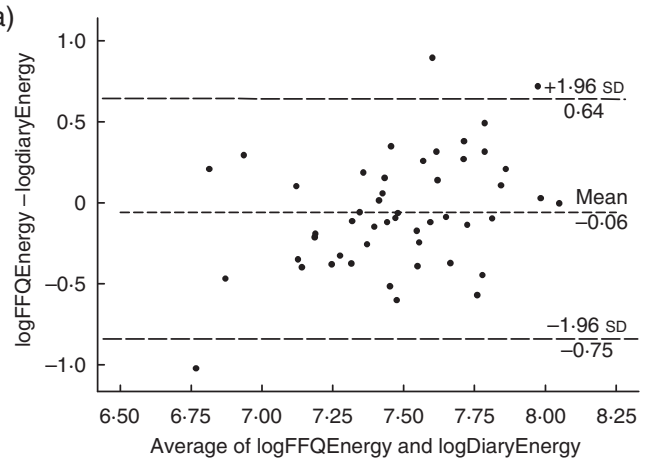

(c)

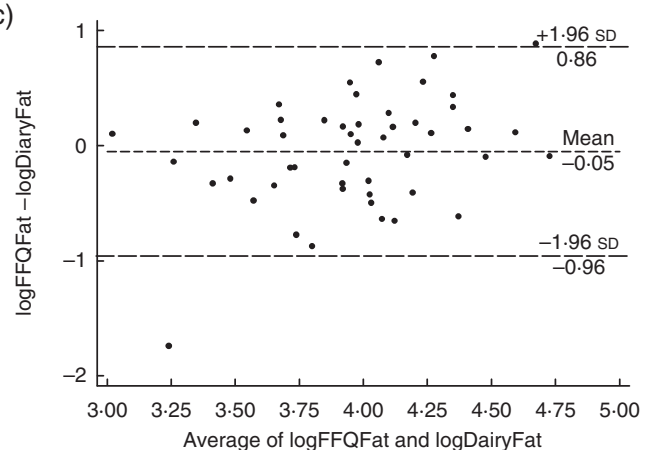

(e)

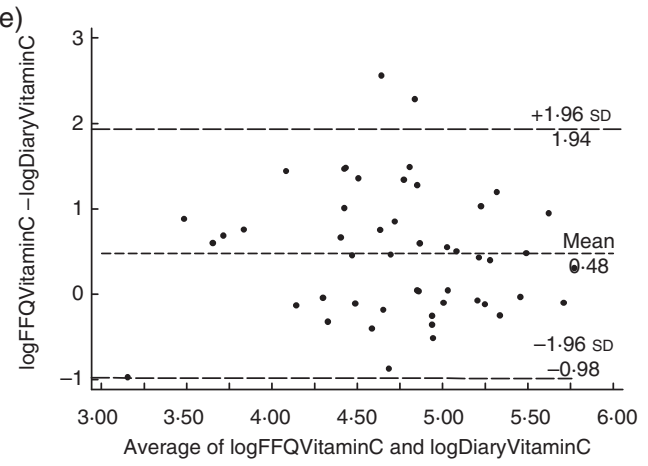

(g)

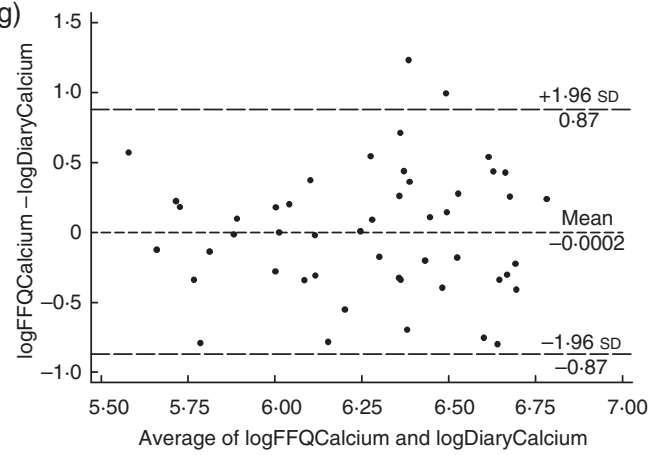

(b)

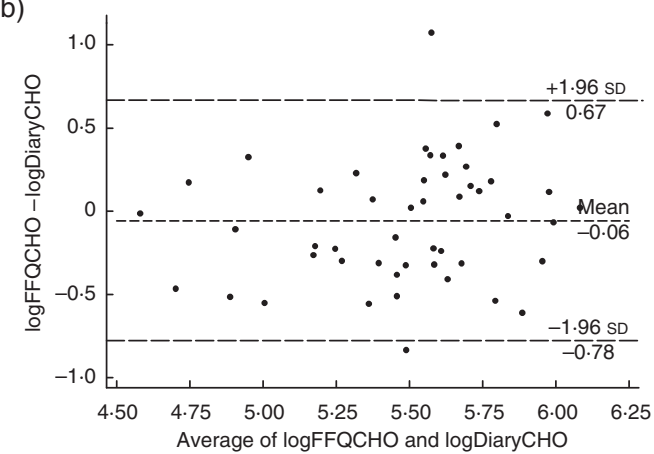

(d)

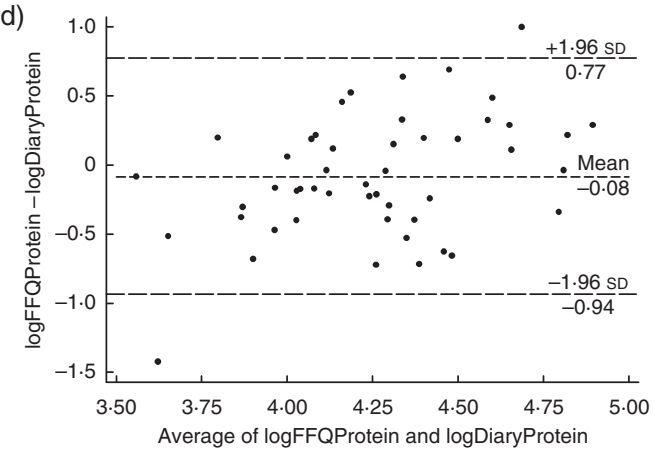

(f)

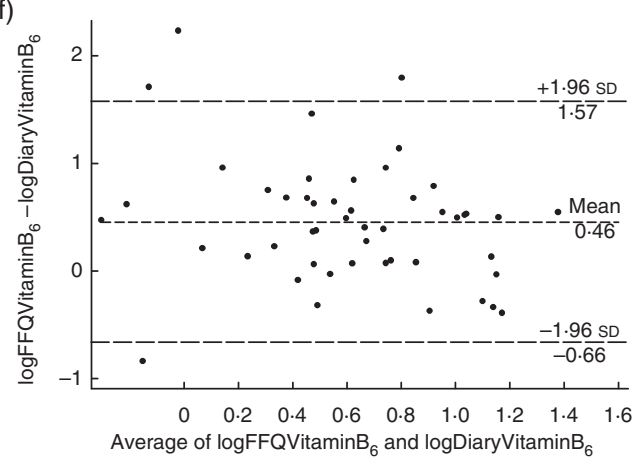

(h)

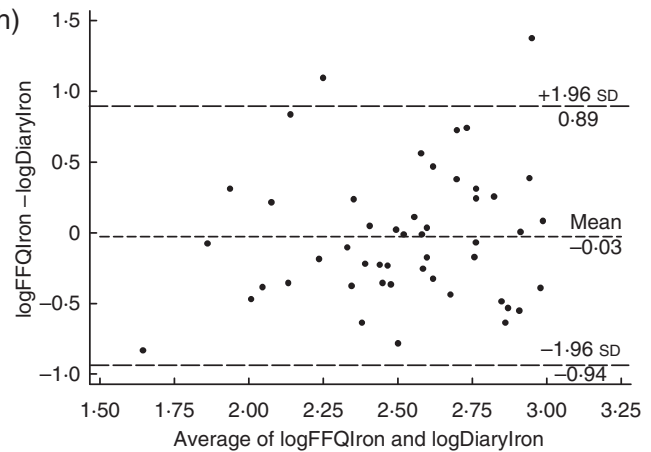

Fig. 2 (a)-(h) Bland-Altman plots showing the relative validity of quantitative FFQ v. $4 \mathrm{~d}$ food diary for energy, carbohydrate $(\mathrm{CHO})$, total fat, protein, vitamin $\mathrm{C}$, vitamin $\mathrm{B}_{6}$, calcium and iron, respectively, based on log-transformed values. Greater degree of agreement between the two methods is observed at higher levels of intake of energy and macronutrients

studies. The observed proportion for gross misclassification for energy and macronutrinets in the present study $(3 \cdot 5 \%)$ was smaller than the Korean $(3 \cdot 8 \%)$ but larger than that reported by the American (1.0\%) and German (1.3\%) studies.
The mean daily intake of macronutrients estimated by the QFFQ and food diary was very similar in the present study. However, utilizing the Bland-Altman plots to assess individual validity showed that agreement between the QFFQ and food diary was inconsistent across the 
range of intake for energy, fat, protein and carbohydrates. Nevertheless, the agreement between the two methods for energy and macronutrients was better among participants who consumed more. This indicates possible under-reporting on the QFFQ for participants who had lower intake of energy, fat, protein and carbohydrates.

The Spearman's correlation coefficients in the present study were similar to those from a study on Jamaicans of African origin (for energy, 0.66 v. 0.69; saturated fat, $0 \cdot 64 v \cdot 0 \cdot 51$, respectively) ${ }^{(16)}$ and far higher than African Americans in the large Multiethnic Cohort study (energy, $0.66 v .0 \cdot 16$; carbohydrate, $0.56 v \cdot 0 \cdot 20$; total fat, $0.59 v$. $0 \cdot 29$; protein, $0 \cdot 44 v \cdot 0 \cdot 17$; calcium, $0.49 v \cdot 0 \cdot 25$, respectively $)^{(10)}$. As data for validation studies on African-origin populations are limited, the results from the present study were compared with the results of validation studies among other ethnic groups. The present study had higher correlations between the QFFQ and food diary for energy, total and saturated fat, protein and carbohydrate when compared with the validation study of a 171-item semi-QFFQ in a Southern California population ${ }^{(17)}$. Compared to the European Prospective Investigation into Cancer and Nutrition study ${ }^{(18)}$, the correlations between QFFQ and food diaries were higher in the present study for total fat $(0.59 v .0 .37)$, protein $(0.44 v .0 .41)$ and carbohydrate $(0.56 v .0 \cdot 41)$, but lower for dietary fibre $(0 \cdot 17 v \cdot 0 \cdot 46)$. A study on sixteen FFQ validated against consecutive food diaries ${ }^{(19)}$ found lower correlations for energy (0.66 v. 0.56) and carbohydrate (0.56 v. 0.53$)$, equal correlations for total fat $(0.59 v .0 .59)$ and higher correlations for protein $(0.44 v \cdot 0 \cdot 47)$, dietary fibre $(0 \cdot 17$ v. 0.49$)$, calcium $(0.49 v .0 .59)$ and vitamin $\mathrm{C}(0.39 v$. $0 \cdot 63)$ compared with the present analysis.

Segovia-Siapco et $a l^{(17)}$ noted that FFQ tend to overestimate dietary intake in contrast to other dietary assessment methods, particularly when the FFQ has more than 100 items. In contrast, a meta-analysis of forty validation studies on $\mathrm{FFQ}^{(19)}$ reported higher correlations with the reference method for most nutrients when comparing longer FFQ with shorter ones; this was observed particularly for protein, energy-adjusted total fat and vitamin $\mathrm{C}^{(19)}$. In the present study, the mean intake of energy and all macronutrients derived from food diaries was the same or higher compared with the QFFQ. Although a review of 227 validation studies by Cade et al. ${ }^{(20)}$ reported total fat as having the highest mean correlation coefficient among all nutrients, the present validation study indicated the highest correlation for carbohydrates (ICC $=0.63$, $\rho=0 \cdot 56$ ).

Intakes of dietary fibre and most micronutrients, particularly vitamin A, obtained from FFQ have been shown to have lower correlations to the reference method compared with the macronutrients ${ }^{(20-22)}$, a trend also observed in the present study. Similar to other studies ${ }^{(23-25)}$, a low correlation was observed for vitamin $\mathrm{E}$ in the validation of the QFFQ against food diaries.
A limitation of our study, and all dietary validation studies, is the lack of a gold standard to assess long-term dietary intake. Biomarkers may be good measures of true nutrient intake; however, they are limited to energy and a few other nutrients and, thus, do not cover the total diet and are costly in analysis ${ }^{(3)}$. Cade et al. reported that only $19 \%$ of the reviewed studies validated FFQ against biomarkers, but $75 \%$ compared FFQ with another dietary assessment method ${ }^{(3,20)}$. The food diary was selected as the reference method since it reflects exact consumption as recording is performed at the time of intake, although food diaries are known to under-report food intake ${ }^{(26-28)}$. However, other methods commonly used to validate QFFQ, such as $24 \mathrm{~h}$ dietary recalls, may lead to a biased validation of the $\mathrm{FFQ}^{(10,29)}$. As shown in the Observing Protein and Energy Nutrition Study, the FFQ and $24 \mathrm{~h}$ recall data were found to have correlated errors and, therefore, using recalls as the reference instrument would overestimate the performance of the $\mathrm{FFQ}^{(30)}$. FFQ and food diaries might also have correlated errors as both rely on the recording of information by the individual; however, this problem may be more pronounced using recalls rather than diaries because both FFQ and $24 \mathrm{~h}$ recalls require the individual to recollect past diet.

The food diaries in the present study were administered during only one season. However, the QFFQ and the food diaries were collected in the same time frame and seasonal variation is not a major factor in the BNCS. Nevertheless, potential biases inherent to these types of studies must be considered. Although participants were asked to record intake of all food and drink items at the time of consumption, this may not have been entirely possible, thus presenting the potential for recall bias. Likewise, participants were provided with specific guidelines and food models to estimate intake; however, one cannot discount the occurrence of underestimation or overestimation in the amount of food and drink and/or portion sizes.

Validation was carried out in the controls only and they are not representative of whole BNCS study population. Patients with cancer were not included in the present study because the disease is highly likely to affect their pattern of food consumption during the 12 months compared with the non-diseased (control) population who generally experience little change over time. The food diary is a proxy for recent dietary intake and among cancer patients it is likely different from the QFFQ data obtained over the 12 months preceding diagnosis. Therefore, we did not include cases in the validation study because using the food diary would not be an accurate reference for the QFFQ. On the other hand, the validated QFFQ in the present study would be applicable to cases because in the case-control study the cases were asked to report frequency and quantity of food intake for the 12 months preceding diagnosis of the disease. Thus, it is likely that their dietary patterns (in terms of consumed food items and portion sizes) were similar to the controls in the present study. 
For the first time, a QFFQ has been developed and validated against food diaries for use in the Africanorigin population in Barbados. Now that this QFFQ is available, as the first validated dietary intake instrument for this population, it will be an important tool to assist with the analysis of diet-cancer associations among these people, known to have more aggressive disease and higher mortality than other groups. This QFFQ provided estimates of usual dietary intake similar to the food diary except for dietary fibre, folate, vitamins $\mathrm{A}, \mathrm{E}$ and $\mathrm{B}_{12}$. The data from the QFFQ can be used to rank the dietary intake of individuals and examine associations of dietary intake with breast and prostate cancer.

\section{Acknowledgements}

The Barbados National Cancer Study (BNCS) was funded by the National Human Genome Research Institute of the United States, National Institutes of Health of the United States, contract no. N01-HG-25487. The research was also aided by the Developmental Funds award from the Cancer Research Center of Hawaii. The authors do not have any conflict of interest to declare. S.S. designed and developed the project, trained the staff in all data collection and oversaw all data analyses. M.P. and S.S. led the writing of the manuscript. X.C. and C.C. collaborated in writing. R.H. oversaw and assisted in data collection. X.C., S.Y.W. and B.N. contributed to data input. All data were reviewed and analysed by X.C., C.C., B.N., S.Y.W., L.R.W. and M.P. M.C.L. oversaw the study design, data analysis, reviewed and edited the manuscript. All authors reviewed and approved the final version of the manuscript. All authors had primary responsibility for final content. The authors are grateful to the Ministry of Health, Barbados, for conducting and sharing the National Nutrition Survey data, and thank all staff and participants in the BNCS, without whose help the QFFQ and food diary data could not have been collected. The authors are grateful for the support and oversight of the Barbados local advisory committee. The present study could not have been undertaken without the help of Nurses Maul and Brown. The authors also thank Ms Eva Erber for her editing and providing valuable comments.

\section{References}

1. Sharma S, Cao X, Harris R et al. (2007) Dietary intake and development of a quantitative food frequency questionnaire for the Barbados National Cancer Study. Public Health Nutr 10, 464-470.

2. Willet W (1998) Nutritional Epidemiology, 2nd ed. New York, NY: Oxford University Press.

3. Cade J, Thompson R, Burley V et al. (2002) Development, validation and utilisation of food-frequency questionnaires - a review. Public Health Nutr 5, 567-587.
4. Kipnis V, Midthune D, Freedman L et al. (2002) Bias in dietary-report instruments and its implications for nutritional epidemiology. Public Health Nutr 5, 915-923.

5. Sharma S, Cao X, Harris R et al. (2008) Assessing dietary patterns in Barbados highlights the need for nutritional intervention to reduce risk of chronic disease. J Hum Nutr Diet 21, 150-158.

6. US Department of Agriculture, Food Surveys Research Group (2004) Food and Nutrient Database for Dietary Studies, 1.O. Beltsville, MD: Agricultural Research Service.

7. US Department of Agricultural Research Service Nutrient Data Laboratory (2005) US Department of Agriculture National Nutrient Database for Standard Reference, Release 18. http://www.nal.usda.gov/fnic/foodcomp/Data/SR18/ sr18.html (accessed December 2005).

8. Sharma S, Harris R, Cao X et al. (2007) Nutritional composition of composite dishes for the Barbados National Cancer Study. Int J Food Sci Nutr 58, 461-474.

9. Snedecor GW \& Cochran WG (1989) Statistical Methods, 8th ed. Ames, IA: Iowa State University Press.

10. Stram DO, Hankin JH, Wilkens LR et al. (2000) Calibration of the dietary questionnaire for a multiethnic cohort in Hawaii and Los Angeles. Am J Epidemiol 151, 358-370.

11. Fleiss JL (2003) Statistical Methods for Rates and Proportions, 3rd ed. Hoboken, NJ: Wiley-Interscience.

12. Bland JM \& Altman DG (1986) Statistical methods for assessing agreement between two methods of clinical measurement. Lancet 1, 307-310.

13. Ahn Y, Kwon E, Shim JE et al. (2007) Validation and reproducibility of food frequency questionnaire for Korean genome epidemiologic study. Eur J Clin Nutr 61, 1435-1441.

14. Osowski JM, Beare T \& Specker B (2007) Validation of a food frequency questionnaire for assessment of calcium and bone-related nutrient intake in rural populations. $J \mathrm{Am}$ Diet Assoc 107, 1349-1355.

15. Kroke A, Klipstein-Grobusch K, Voss S et al. (1999) Validation of a self-administered food-frequency questionnaire administered in the European Prospective Investigation into Cancer and Nutrition (EPIC) Study: comparison of energy, protein, and macronutrient intakes estimated with the doubly labeled water, urinary nitrogen, and repeated 24-h dietary recall methods. Am J Clin Nutr 70, 439-447.

16. Jackson M, Walker S, Cade J et al. (2001) Reproducibility and validity of a quantitative food-frequency questionnaire among Jamaicans of African origin. Public Health Nutr 4, 971-980.

17. Segovia-Siapco G, Singh P, Jaceldo-Siegl K et al. (2007) Validation of a food-frequency questionnaire for measurement of nutrient intake in a dietary intervention study. Public Health Nutr 10, 177-184.

18. Bohlscheid-Thomas S, Hoting I, Boeing $\mathrm{H}$ et al. (1997) Reproducibility and relative validity of energy and macronutrient intake of a food frequency questionnaire developed for the German part of the EPIC project. European Prospective Investigation into Cancer and Nutrition. Int $J$ Epidemiol 26, Suppl. 1, S71-S81.

19. Molag ML, de Vries JH, Ocké MC et al. (2007) Design characteristics of food frequency questionnaires in relation to their validity. Am J Epidemiol 166, 1468-1478.

20. Cade J, Burley VJ, Warm DL et al. (2004) Food-frequency questionnaires: a review of their design, validation and utilisation. Nutr Res Rev 17, 5-22.

21. Ocke MC, Bueno-de-Mesquita HB, Pols MA et al. (1997) The Dutch EPIC food frequency questionnaire. II. Relative validity and reproducibility for nutrients. Int J Epidemiol 26, Suppl. 1, S49-S58.

22. Jain MG, Rohan TE, Soskolne CL et al. (2003) Calibration of the dietary questionnaire for the Canadian Study of Diet, Lifestyle and Health cohort. Public Health Nutr 6, 79-86.

23. Mayer-Davis EJ, Vitolins MZ, Carmichael SL et al. (1999) Validity and reproducibility of a food frequency interview 
in a multi-cultural epidemiologic study. Ann Epidemiol 9, 314-324.

24. Flagg EW, Coates RJ, Calle EE et al. (2000) Validation of the American Cancer Society Cancer Prevention Study II Nutrition Survey Cohort Food Frequency Questionnaire. Epidemiology 11, 462-468.

25. Kumanyika SK, Mauger D, Mitchell DC et al. (2003) Relative validity of food frequency questionnaire nutrient estimates in the Black Women's Health Study. Ann Epidemiol 13, 111-118.

26. Black AE, Prentice AM, Goldberg GR et al. (1993) Measurements of total energy expenditure provide insights into the validity of dietary measurements of energy intake. J Am Diet Assoc 93, 572-579.
27. Haraldsdottir J, Tjonneland A \& Overvad K (1994) Validity of individual portion size estimates in a food frequency questionnaire. Int J Epidemiol 23, 786-796.

28. Lindroos AK, Lissner L \& Sjostrom L (1993) Validity and reproducibility of a self-administered dietary questionnaire in obese and non-obese subjects. Eur J Clin Nutr 47, 461-481.

29. Thompson FE, Kipnis V, Midthune D et al. (2008) Performance of a food-frequency questionnaire in the US NIH-AARP (National Institutes of Health-American Association of Retired Persons) Diet and Health Study. Public Health Nutr 11, 183-195.

30. Kipnis V, Subar AF, Midthune D et al. (2003) Structure of dietary measurement error: results of the OPEN biomarker study. Am J Epidemiol 158, 14-21. 